\title{
Clinical Profile and Outcome of Envenomous Snake-Bite At Tertiary Care Centre In Nellore- A Retrospective Study
}

\author{
Dr.Y. Gangadharam, Dr. Sk. Noushad Ali, Dr. Shabana \\ begum.sk,Dr.D.Srinivasa Rao \\ Assistent professor, Department of medicine, ACSR medical college, Nellore. \\ Assistent professor, Department of medicine, ACSR medical college, Nellore. \\ Department of Public Health Dentistry, Narayana Dental College and Hospital, Nellore, Andhra Pradesh, India \\ Professor,Department of medicine,ACSR medical college,Nellore
}

\begin{abstract}
:
Aims: To study the prevalence of poisonous and non-poisonous snake bites in nellore district with reference to age, sex, occupation, part of body bitten, time of bite and seasonal variation, and the types of poisonous snakes common in this locality and their clinical manifestations along with the systemic envenomation from various types of poisonous snakes and their effective management in reducing the mortality rate.

Materials and Methods: This was a retrospective study conducted between May 2015 to May 2016 at government general hospital, nellore

Result: A total of 123 patients were studied in our hospital. Out of 123, 63 patients were of poisonous snake bite and 60 patients were of non-poisonous snake bite. Out of these 63 poisonous snake bites, 35 were viperine snake bites, 20 were neuroparalytic snake bites and 8 were locally toxic (LT) snake bites.

Conclusion: Snake bite is a common life-threatening emergency in the study area. Delay in hospitalization is associated with poor prognosis and increased mortality rate due to consumptive coagulopathy, renal failure, and respiratory failure. Unusual complications like pulmonary edema, intracerebral hemorrhage, ischemic infarcts,Disseminated intravascular coagulation (DIC) were observed in present study.
\end{abstract}

Keywords: Non-poisonous bite, neuroparalytic bite, poisonous bite, vasculotoxic bite

\section{Introduction}

Snake bite is a common medical emergency and an occupational hazard, more so in tropical India, where farming is a major source of employment. Over 2,000 species of snakes are known worldwide, of which around 400 are poisonous. These snakes belong to the families Elapidae, Viperidae, Hydrophiidae and Colubridae ${ }^{1}$ Viper bites are more common than other poisonous snakebites in human beings ${ }^{2,3}$. Of the different varieties of vipers, the Russell's viper (Vipera russelli) commonly inhabits the Southern Asian countries, and the Russell's viper's bite is regarded as an occupational hazard for the farming community ${ }^{4}$.

Every year, 50,000 Indians die in 2, 50,000 incidents of snake bite, despite the fact that India is not home for the largest number of venomous snakes in the world, nor is there a shortage of anti-snake venom in the country ${ }^{5}$. The main cause of this "unacceptable incidence" of snake bite fatalities is that people try out all kinds of "bizarre locally available remedies" initially, instead of going to the nearest hospital. The available data on the epidemiology of snakebite from the Indian subcontinent are sparse, because most of the snake bites occur in illiterate, rural people who use witchcraft and traditional healers. Only the cases of snakebite with severe envenomation reach the healthcare centres ${ }^{4}$.

Snakebite is a common acute medical emergency faced by rural populations in tropical and subtropical countries. There are no accurate records available to determine the exact epidemiological or even mortality in snakebite cases in Nellore, Andhrapradesh. In India more than 20,00,000 snake bites are reported annually, of which 35,000 to 50,000 people die ${ }^{6}$. Its public health importance has been largely ignored by medical science. Snake-bites are the common ${ }^{5}$ cause of morbidity and mortality in tropical countries. In India, there are 216 species of snakes, of which only four are venomous snakes (cobra, krait, Russell's viper and saw scaled viper). Snake venoms are rich in protein and peptide toxins that have specificity for a wide range of tissue receptors, making them clinically challenging and scientifically interesting, especially for drug design ${ }^{7}$.Although the full burden of human suffering attributable to snake bite remains uncertain, hundreds of thousands of people are known to be envenomed and tens of thousands are killed by snakes every year. South Asia is the world's most heavily affected region, due to its high population density, widespread agricultural activities, numerous venomous snake species and lack of functional snake bite control programs. Poorly informed rural populations often apply inappropriate fi rst-aid measures and vital time is lost before the victim is transported to a treatment centre, where cost of treatment can constitute an additional hurdle ${ }^{8,9}$.The deficiency of snake bite management 
in South Asia is multi-causal and requires joint collaborative efforts from researchers, anti-venom manufacturers, policy makers, public health authorities and international funders ${ }^{10}$.

Snake-bite is one of the most life-threatening bio-weapon system in the nature which may cause local to systemic complications in the form of neurotoxicity or haematotoxicity. This study was conducted at tertiary care centre in Nellore,Andhrapradesh which is one of the agricultural areas, to determine the clinical profile, complications and outcome of envenomous snake-bite cases.

\section{Material \& Methods}

This was a retrospective, observational study conducted between May 2015 to May 2016 at tertiary health care centre in Nellore,Andhra Pradesh, India. The records of the snakebite victims who attended the hospital were obtained from the medical records department. This department uses the ICD-10 system for the classification of diseases Out of 123 admitted snakebite 60 were non poisonous snake bite and 63 were poisonous snakebites. Clinical data including age, sex and occupation of the victims, the site of bite,

time of bite, time between bite and presentation, clinical manifestations, complications and outcome were obtained from the case records.

ASV was recommended if one of the following features were observed in patients with history of snake-bite 1. Local swelling more than half of the bitten limb in absence of tourniquet, rapidly increasing edema and development of compartmental syndrome.

2. Development of tender enlarged lymph-nodes

3. Blister formation over involved limb

4. Spontaneous bleeding from bite site, venous puncture site, haematuria

5. Positive 20 minute whole blood clotting test

6. Vomiting, contraction of frontalis, ptosis, blurring of vision, parasthesia around mouth

7. Hypotension, shock, arrhythmias

8. Dark colour urine, oliguria, anuria

The mortality was defined at necropsy and on the basis of the death certificates. The statistical analysis was conducted by using the Statistical Package for the Social Sciences, version 11.0

\section{Results}

Table 1 Sex incidence of snake bites

\begin{tabular}{|l|c|l|l|}
\hline sex & No of poisonous cases & No of non poisonous cases & $\%$ \\
\hline male & 45 & 36 & 65.8 \\
\hline female & 18 & 24 & 34.14 \\
\hline
\end{tabular}

Table 2 Incidence of snake bite with reference to site of bite

\begin{tabular}{|l|c|c|}
\hline Site of bite & No of non-poisonous cases & No of poisonous cases \\
\hline Upper extremity & 03 & 08 \\
\hline Lower extremity & 57 & 55 \\
\hline Trunk & - & - \\
\hline
\end{tabular}

Table 3 Relation of time with snake bite

\begin{tabular}{|l|c|l|}
\hline & No of non-poisonous cases & No of poisonous cases \\
\hline Afternoon (12:00PM-4:00PM & 07 & 04 \\
\hline Evening(4:00PM-8:00PM) & 30 & 37 \\
\hline Night (8:00PM-6:00AM) & 13 & 12 \\
\hline Morning(6:00AM-12:00PM) & 10 & 10 \\
\hline
\end{tabular}

Table 4 Seasonal incidence of snake bite

\begin{tabular}{|l|l|l|}
\hline & No of non poisonous cases & No of poisonous cases \\
\hline Monsoon(june-sept) & 21 & 15 \\
\hline Winter(oct-feb) & 9 & 9 \\
\hline Summer(march-may) & 30 & 39 \\
\hline
\end{tabular}


Table 5 Incidence of snake seen and brought

\begin{tabular}{|l|c|l|}
\hline & No of non poisonous cases & No of poisonous cases \\
\hline Seen and brought & 06 & 09 \\
\hline Seen not brought & 30 & 51 \\
\hline Not seen & 24 & 3 \\
\hline
\end{tabular}

Table 6 Incidence of poisonous snake bite with local toxicity

\begin{tabular}{|l|l|l|}
\hline & No of VT cases & No of NT cases \\
\hline With local toxicity & 33 & 16 \\
\hline Without local toxicity & 02 & 04 \\
\hline
\end{tabular}

Table 7 Loss of time from the bite till the admission

\begin{tabular}{|l|l|llll|}
\hline \multirow{2}{*}{ Time } & $\begin{array}{l}\text { No of non-poisonous } \\
\text { cases }\end{array}$ & \multicolumn{4}{|l|}{ No of poisonous cases } \\
\cline { 2 - 5 } & & VT & NT & LT & Death \\
\hline Within 6 hrs & 38 & 19 & 14 & 01 & - \\
\hline $6-24 \mathrm{hrs}$ & 22 & 12 & 05 & 02 & 02 \\
\hline$>24 \mathrm{hrs}$ & 0 & 04 & 01 & 05 & 01 \\
\hline
\end{tabular}

Table 8 The number of patients who received first-aid

\begin{tabular}{|l|l|lcc|}
\hline & $\begin{array}{l}\text { No of non- } \\
\text { poisonous cases }\end{array}$ & \multicolumn{3}{|c|}{ No of poisonous cases } \\
& VT & NT & LT \\
\hline Tourniquet & 18 & 20 & 09 & 04 \\
\hline ASV & & 40 & 02 & 02 \\
\hline False beliefs & & 03 & 03 & 02 \\
\hline No Rx & 42 & 08 & 06 & \\
\hline
\end{tabular}

Table 9 Incidence of local toxicity in poisonous snake bite

\begin{tabular}{|l|c|c|c|}
\hline & LT & VT & NT \\
\hline Pain & 08 & 30 & 09 \\
\hline Local bleed & 09 & 31 & 02 \\
\hline Cellulitis & 03 & 23 & 04 \\
\hline Gangrene & 00 & 07 & 01 \\
\hline
\end{tabular}

Table 10 Incidence of symptomatology of neuro paralytic snake bite poisoning

\begin{tabular}{|l|c|}
\hline & No of cases $(\%)$ \\
\hline Ptosis & $20(100)$ \\
\hline Dysphagia & $07(35)$ \\
\hline Ophthalmoplegia & $15(75)$ \\
\hline Unconsciousness & $04(20)$ \\
\hline Flaccid limb paralysis & $04(20)$ \\
\hline Convulsions & - \\
\hline Cellulitis & $07(35)$ \\
\hline Respiratory paralysis & $15(75)$ \\
\hline
\end{tabular}

Table 11 Incidence of symptomatology in viperine snake bite

\begin{tabular}{|l|l|}
\hline & No of cases(\%) \\
\hline Local bleed & $31(88.57)$ \\
\hline Hum bleed & $02(5.7)$ \\
\hline Epistaxis & $01(2.8)$ \\
\hline Hematemesis & $01(2.8)$ \\
\hline Malena & $02(5.7)$ \\
\hline Hematuria & $02(5.7)$ \\
\hline Oliguria & $14(40)$ \\
\hline Echymosis & $16(45.7)$ \\
\hline Intracerebral hemorrhage & $01(2.8)$ \\
\hline Pulmonary edema & $01(2.8)$ \\
\hline Intracerebral haemorrhage with infarcts & $01(2.8)$ \\
\hline
\end{tabular}

Table 12 Incidence of complications of vasculotoxic snake bite

\begin{tabular}{|l|l|l|l|l|}
\hline VT & AKI & Sec.infec & DIC & Death \\
\hline 35 & 20 & 9 & 3 & 3 \\
\hline
\end{tabular}


Table 13 Type of treatment received in vasculotoxic snake bite

\begin{tabular}{|l|l|}
\hline ASV & 35 \\
\hline Diuretics & 14 \\
\hline Hemodialysis & 06 \\
\hline Blood transfusion & 03 \\
\hline
\end{tabular}

Table 14 Duration of neuroparalytics on ventilator

\begin{tabular}{|l|l|}
\hline Duration & No of cases \\
\hline Less than 12 hours & 08 \\
\hline $12-24$ hours & 03 \\
\hline$>24$ hours & 01 \\
\hline
\end{tabular}

Table 15 Incidence in relation to condition at discharged

\begin{tabular}{|l|l|l|l|}
\hline & LT & NP & VT \\
\hline Complete recovery & 13 & 17 & 10 \\
\hline complications & 0 & 1 & 28 \\
\hline death & 0 & 3 & 4 \\
\hline
\end{tabular}

Table 16 Comparative mortality in poisonous snake bite

\begin{tabular}{|l|c|c|c|}
\hline & No . of cases & No .of deaths & $\%$ \\
\hline Neuroparalytic & 20 & 3 & 04.76 \\
\hline Vasculo toxic & 35 & 4 & 06.36 \\
\hline Locally toxic & 8 & 0 & 0 \\
\hline
\end{tabular}

In all, 123 patients of snake bite were studied. Out of 123 patients, 60 patients had non-poisonous snake bites and 63 patients had poisonous snake bites.Among males $(65.85 \%)$ were bitten more than females (34.14\%)(Table 1).

Maximum bites were in the evening $(54.47 \%)$ than day time. Higher incidence of snake bites was found in summer (56.09\%) i.e. March to May (Table 3and4).

In fifteen cases, the snakes were seen/identified(Table 5).

A total of $58.53 \%$ patients reported to medical help within 6 hours, among which $28.45 \%$ were VT and $16.26 \%$ were NT(Table 7).

Sixty one patients came with tourniquet application, out of which 43 had poisonous bite, in that 8 patients had received ASV. Fifty eight cases did not receive any sort of medical help before admission(Table 8).

Time of onset of systemic manifestation was earlier in neuroparalytic snake bites than VT snake bite. VT snake bites (28\%) were more common than neuro paralytic bites (14.66\%). Commonest VT manifestation was local bleed $(88.57 \%)$ and next on the list was oliguria $(54.7 \%)$ fallowed by opthalmoplegia and respiratory paralysis (Table 9).

Ptosis (100\%) was the commonest and earliest manifestation of neuroparalytic snake bite fallowed by opthalmoplegia and respiratory paralysis(Table 10).

Out of VT snake bites, 31(88.57\%) showing local bleeding, 16(45.7\%)showing oliguria.Among VT snake bites 20 were of AKI, 6 required hemodialysis. Three DIC patients received blood transfusion. Fourteen patients of AKI received diuretics and recovered completely. Eight cases were LT; out of them, 3 patients developed cellulitis. (Table 11,12,13).

Total 22 bites of neuroparalytic bite twelve patients required artificial ventilation, more patients are in less than 12 hours. (Table 14)

Total 31 patients showed complete recovery, among them 14 LT, 15 NT and 9 VT. In that total deaths are 5 among 2 from NT and 3 from VT. (Table 15)

Total 22 bites of neuroparalytic bite twelve patients required artificial ventilation. Totally seven patients died because they came late to seek medical treatment and by that time, complications were beyond control and were associated with systemic infection. (Table 16)

\section{Discussion}

In India, the poisonous snakes belong to the elapid family of the cobra and krait and the viper family of the Russel's viper and the saw scaled viper. Envenomation attributable to elapid bites causes paralysis of the ocular, bulbar, and limb girdle muscles. Viper bites mainly cause bleeding from mucocutaneous sites, haemolysis, acute kidney injury, and occasionally shock ${ }^{11}$.

In India, it is believed that 2 lakh people are bitten by snakes and about 15,000-30,000 cases/year prove fatal $^{12}$. In the present study, 123 cases of snake bites including poisonous and non-poisonous bites were studied in the medical wards and intensive care unit of government general hospital,nellorefrom $1^{\text {st }}$ May 2015 to $31^{\text {st }}$ 
May 2016. The number of poisonous cases were 63 and the number of non-poisonous cases were 60. Among the poisonous snake bites, the number of Viperine bites were 35, the number of neuroparalytic bites were 20 and the number of LT cases were 8 .

In the present study, $81(61.5 \%)$ patients were male victims, whereas the female victims were 42 $(34.14 \%)$ in number. All the previous reports mention the same findings. Ahuja and $\mathrm{Singh}^{13}$ in $^{1954}$ reported the ratio as 4:1 (M: F). Bhat et al $^{14}$. in 1974 reported the incidence as 7:3 (M: F) ${ }^{14}$. Among male patients, 61 were poisonous, whereas in females, 15 were poisonous snake bites.

In lower extremities bites are $112(68.71 \%)$ and in upper extremities $11(8.94 \%)$. Among them, upper extremity poisonous cases were 8 and lower extremity poisonous cases were 55 . Reid ${ }^{15}$ mentions that most of the bites in tropical countries are on lower extremities because the victims are bitten by treading on or near the snake, while in non-tropical countries most bites are on fingers and hands because the victim deliberately handles the snake.

In the present study, the day was divided into four groups. Maximum number of cases were detected in the interval between 4.00 PM to 8.00 PM. The documented figure was 67 among 123 patients. Next on the list was the time interval between 8.00 PM to $6.00 \mathrm{AM}$ where number of patients bitten was 25 . These results are close to study's conducted by Virmani and Dutt ${ }^{16}$ They have noted $12 \%$ cases during day time.

In the present study, higher incidence was found in summer (March to May), 69 (56.09\%) were total snake bites in summer, among them 39 were poisonous bites and 30 were non-poisonous bites. Followed by monsoon where the total number of snake bites was 36, among which 15 were poisonous bites and 6 were nonpoisonous. Neuroparalytic snake bites were more at the end of summer and beginning of monsoon. Incidence of VT bites was comparatively more in winter. Study conducted by Banerjee ${ }^{17}(1978)$ et al noted that incidence of $70-80 \%$ during May to October. Most human snakebites occur during the monsoon season because of flooding of the habitat of snakes and their prey. It is the life cycle of the natural prey of these reptiles that govern contact with humans. The breeding habits of frogs closely follow the monsoons and rats and mice are always in close proximity to human dwellings. From another south Indian study snakebites abound during the months of October to December (33\%) and May to July (67\%).

In the present study, 15 patients had brought snakes along with them and they were identified in this hospital. Among them 8 were poisonous snakes(three were cobras, three vipers, one was Krait, and two were echiscarinatus).

In the present study, $72(58.53 \%)$ patients were admitted within first 6 hrs. Among which 19 cases were VT and 14 were neuroparalytic. In poisonous cases twenty two patients were admitted within the first 24 hrs but after 6 hrs, among which 15 were VT and 5 were NT and 2 were LT. Two NT bites expired within 1 to 2 hrs after admission. A study conducted by Lahoriet al., in 135 patients, $85 \%$ patients were admitted in the first 24 hours after bite.

Among 123 patients, $51(41.46 \%)$ had applied tourniquet. Out of 51 patients, 33 were poisonous bites and 18 non-poisonous bites. Out of 33 cases of poisonous bites, 20 were VT, 9 were neuroparalytic, and 4 were LT bites. A study conducted by George Watt et $a l^{18}$ (May 1988), tourniquet was applied in $94 \%$ patients, 4 were asymptomatic prior to release of their tourniquet, and in 11 patients symptoms worsened precipitously.

In the present study, 47 (74.60\%) patients had local pain. Among which 8 (12.69\%) were LT, 30 (47.61\%) were VT and 9 (14.28\%) were neuroparalytic bites.

Local cellulitis was seen in $23(65.71 \%)$ patients of VT snake bite and $4(18.18 \%)$ patients of neuroparalytic snake bites. A total of 31 of the patients in the present study had local bleeding. Out of which 4 patients had LT bite, 25 patients had VT bite and 2 patients had neuroparalytic snake bites. In the present study, $2(5.7 \%)$ patients had gum bleeding but Purohit (1944) described gum bleeding as the commonest manifestation of viperine bite. In our study, $14(40 \%)$ patients had hematuria these results are in contrast with study conducted by Corkill $^{19}(1956)$ described hematuria as the commonest manifestation. In our study Ecchymosis was present in $1(2.8 \%)$ patients but these results are in contrast with study conducted by Bhat (1974) described ecchymosis in $43 \%$ of patients. Hematemesis was present in $2(5.7 \%)$ patients in the present study, whereas Bhat ${ }^{14}$ showed $^{2}$ that 37 patients among 310 patients had hematemesis. In the present study, $1(2.8 \%)$ patients had haemoptysis and $1(2.8 \%)$ patient had epistaxis.

In the present study, $100 \%$ patients developed ptosis among 20 cases of Neuroparalytic bite. Ophthalmoplegia was seen in $15(68.18 \%)$ patients of Neuroparalytic bite. Four (18.18\%) patients became unconscious, $3(13.63 \%)$ patients with flaccid limb paralysis, $15(68.8 \%)$ patients developed respiratory paralysis, among which 13 patients needed respirator.AKI was seen in 20/35, 57.14\% of patients of VT bite. In all the cases of ARF except one, DIC was the cause for it.

In the present study, 7 patients died of poisonous snake bites out of which $3(4.74 \%)$ were neuroparalytic bite patients and 4 were VT bite patients. All neuroparalytic bite patients died because of delay in receiving respiratory assistance. Among four deaths of VT bites, three patients died of acute renal failure, and 
one patient died of DIC and intracerebral hemorrhage. Lahori et al. (1981) showed mortality rate to be $2 \%$ and 3 deaths were due to central nervous system (CNS) involvement.

In the present study, 35/123 patients received ASV. According to Reid et al., ASV is not very effective against local effects of venom. In the present study, 31/63 reversed completely. Three deaths in neuroparalytics were because of delay in administration of ASV producing respiratory paralysis and delay in ventilatory support who were transferred from other hospital to our hospital.

In the present study, four $(11.42 \%)$ patients of viperine snake bites received blood transfusions. Saini ${ }^{20}$ et al. (1984) and Reid et al. feel that blood transfusion is not required routinely.

In the present study, among 20 patients of neuroparalytic bite , 12 needed ventilatory support.Among which 3 patients died. Total duration of ventilator was less than $24 \mathrm{hrs}$ for most of the patients except one.

\section{Conclusion}

Snake bite is a common life-threatening emergency in the study area. Spreading cellulitis, DIC and AKI were the common complication with vasculotoxic snakebite. Unusual complications like pulmonary edema, intracerebral hemorrhage, Disseminated intravascular coagulation (DIC),intracerebral hemorrhage with infarcts were observed in present study. Delay in hospitalization is associated with poor prognosis and increased mortality rate due to consumptive coagulopathy, acute kidney injury, and respiratory failure. Ready availability and appropriate use of anti-venom, ventilatory support, hemodialysis, and treatment of DIC and close monitoring of patients in the hospital will help to reduce mortality from snakebites. Early administration of ASV prevents respiratory paralysis after neuroparalytic snake bite. Patients with evidence of respiratory insufficiency after neurotoxic venom poisoning require timely intubation and artificial ventilation. There is a definite more need to educate the public about the hazards of snakebite, early hospital referral and treatment. There is a need to educate the public especially rural regarding warning signs of envenomation and hazards of delayed hospitalization.

[1]. Al-Homrany M. Acute renal failure following snake bites: a case report and review of the literature. Saudi J Kidney Dis Transpl. 1996;7:309-12.

[2]. Basu J, Majumdar G, Dutta A, et al. Acute renal failure following snake bites (viper). J Assoc Physicians India. 1977; 25:883-90

[3]. Bhat RN. Viperine snake bite poisoning in Jammu. J Indian Med Assoc. 1974; 63:383-92.

[4]. Halesha B.R., Harshavardhan L., Lokesh A J., Channaveerappa P.K., Venkatesh K.B. Study on the Clinico-Epidemiological Profile and the Outcome of Snake Bite Victims in a Tertiary Care Centre in Southern India. Journal of Clinical and Diagnostic Research. 2013 January, Vol-7(1): 122-126

[5]. Simpson ID, Norris RL. Snakes of medical importance in India: Is the Concept of the" Big 4" still relevant and useful? Wilderness Environ Med. 2007; 18:2-9.

[6]. Alirol E, Sharma SK, Bawaskar HS , Kuch U , Chappuis F. Snake bite in South Asia: a review PLoS Negl Trop Dis. 2010 ; 26;4(1) : e603.

[7]. David AW . Guidelines for the clinical management of snake-bites in the south-east Asia region. World Health Organization, Regional Offi ce for South East Asia, New Delhi : 2005 . p. 1 - 67

[8]. Warrell DA . Guidelines for clinical management of snake bites in South East Asian region . SEAMEOTROPMED - Regional Centre for Tropical Medicine, WHO. 1999. Available from: http://www.searo.who.int/ LinkFiles/SDE_mgmt_snake-bite.pdf .

[9]. Paul V , Pratibha S, Prahlad KA, Earali J , Francis S , Lewis F. High- dose anti snakevenom versus low dose antisnakevenom in the treatment of poisonous snake bites-A critical study . J Assoc Physicians India $2004 ; 52: 14-7$.

[10]. Warrell DA. Snake bite. Lancet. 2010 Jan $2 ; 375$ ( 9708$): 77-88$.

[11]. Reid HA, Theakston ROG. The management of snake bite. Bull World Health Organ 1986;61:885-95.

[12]. Swaroop and Grab. Snake bite Mortality in world. Vol. 10. WHO bulletin; 1954. p. 35.

[13]. Ahuja MM. Progress in clinical medicine in India. Second Series;1978. p. 136-77.

[14]. Bhat RN. Viperine snake poisoning in Jammu. J Indian Med Assoc 1974;63:383-92.

[15]. Reid HA, Theakston RD. The management of snake bite. Bull WHO 1983;61:885-95.

[16]. Virmani SK, Dutt OP. A profile of snake bite poisoning in Jammu region. J Indian Med Assoc. 1987;85:132-4.

[17]. Banerjee RN. Poisonous snakes of India, progress in, clinical medicine' in India. In: Ahuja MS, editor. 1st ed. 1987.p. 136-1.77.

[18]. Watt G, Padre L, Tuazon ML, Theakston RD, Laughlin LW. Tourniquet application after cobra bite: Delay in the onset of neurotoxicity and the dangers of sudden release. Am J Trop Med Hyg. 1988:38:618-22.

[19]. Corkill NL, Venoms EE, Euckley, Porges N. Washington D.C: 1956. p. 331.

[20]. Saini RK, Sharma S, Singhs, Pathania NS. Snake bite poisoning: A preliminary report. J Assoc Physicians India. 1984;32:195-7. 